\title{
Des de BAIX, A TRAVÉS DELS POBLES
}

\author{
Salir del silencio. Voces de Càlig 1900-1938 \\ Martha E. Heard \\ Onada Edicions, 2013 \\ 216 pàgs. 18 euros
}

\section{Pròleg:}

$\mathrm{L}$

a professora Martha E. Heard fa història local, però amb la intenció de fer, a través d'aquesta, «una història des de baix», és adir, el que importa és allò que li passa al poble i no als monarques i als oligarques.

Ella amb la seua història ens explica el passat de Càlig, però no per a fer localisme; sinó per a contribuir a fer una història més científica i més global.

Altrament, de forma indirecta, ens fa una crida a fer tots plegats la història local de cada poble del País Valencià, però segons ella suggereix cal fer-la amb el suport de les fonts orals, la qual cosa és completament

1 Martha E. Heard, va nàixer en Chicago, Illinois, en 1937. Es va doctorar en la Universitat de St. Louis, Missouri, on s'especialitzà en el teatre de Benito Pérez Galdós. Ha donat conferències en Estats Units i en Espanya. Per a més informació sobre l'autora «Www.caligoralhistory.com».

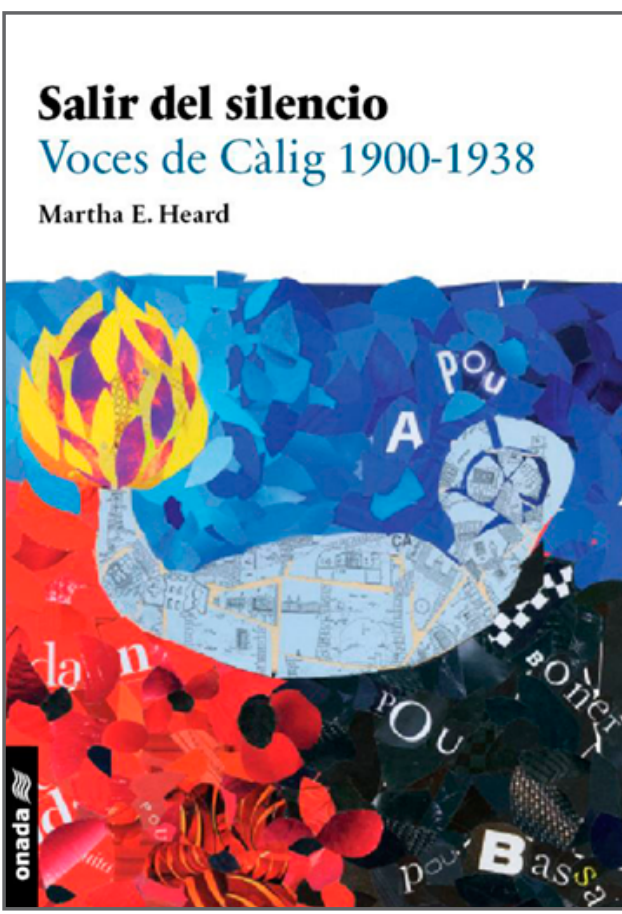

necessària si volem fer una història més humana i més global del poble valencià.

Amb la seua història oral, i a través de l'empatia, entra, i ens fa entrar als lectors, en el món de les persones entrevistades, en el món dels seus protagonistes, també en la vida quotidiana de tot el poble de Càlig. Dit altrament, després de llegir el llibre 
acabes estimant els protagonistes, i, fins i tot, arribes a voler imitar molts dels seus comportaments.

Cal ressaltar que la majoria dels protagonistes de la seua història son herois lluitadors antifeixistes, però anarquistes. Algunes són persones molt idealistes i força lluitadores que viuen intensament les seues idees. Les vides d'aquestes persones ens impulsen a imitar-les, perquè practiquen allò que ha explicat Eric From: «El ser és millor que el tenir».

La nostra amiga Martha té el valor, en aquest llibre, de plasmar de forma vivencial els principals valors de la utopia del comunisme llibertari: la solidaritat amb les persones pobres, una solidaritat de classe; la igualtat, la llibertat, però aquella que és entesa com a una emancipació dels poders opressors representats per: la monarquia, la dictadura i la majoria de l'Església jeràrquica.

\section{Aportacions històriques i histo- riogràfiques de primera part del llibre (1900-1930)}

Els tres primers capítols tenen el mèrit d'explicar les causes del gran analfabetisme a les comarques del nord del País Valencià encara en l'època de la República i la Guerra Civil. L'entrevista a Daniel Gil Beltran ho deixa força evident: «A la escuela no iba nadie porque los llevaban a coger aceitunas»».

A més a més, aquesta part del llibre té el mèrit de transportar-nos a la vida quotidiana de principis del segle xx. Llavors era una vida molt dura, els entrevistats diuen: «Es vivia amb molt de treball, sol i pols, i pares molt estrictes». Tanmateix, les històries que llavors contaven els habitants de Càlig al foc de la llar o a la porta de casa a l'hivern, hi feien més fàcil l'existència tan dura. En aquesta època les dones treballaven en l'agricultura, replegar olives, garrofes, etc. Però: «Al avemaria y a las seis en casa todas y la que se quedaba fuera era una perdida».

Ella ens descriu, en els primers capítols, la forma de ser pròpia de Càlig i també de molts pobles veïns. Explica com van anar evolucionant cap a una major conscienciació dels interessos diferenciats del bloc social dominant respecte el de les classes populars. Va ser 1'emigració a França i a Barcelona el factor gairebé determinant, el que impulsà aquesta evolució. 
A través de la rivalitat entre Cervera i Càlig, plasma com encara, a principi del segle $\mathrm{xx}$, no hi havia una diferenciació ideològica i política al si del conjunt del poble, llavors era encara un poble global, perquè no estava diferenciat en grups polítics ni en classes. Així doncs, el poble era el subjecte històric, un subjecte col·lectiu unitari. Així que aquest actuava tot unit formant un tot global. Fins al punt que en aquesta rivalitat que hi havia contra el poble de Cervera va fer que alguns del poble de Càlig — «ni se sap qui...!»— mataren allà un influent jutge de Cervera, en 1907. El poble es va manifestar totalment unit, en tot el que envoltava aquest fet, fins al punt que la Guàrdia Civil no va poder indagar qui havia matat el jutge; atès que la matança del jutge era el símbol de la justícia incompetent d'aleshores. El mataren tots a una com a Fuenteovejuna.

Per tant, quan els protagonistes de la seua història, que ja havien emigrat, tornen en 1922 a Càlig; aquest era ja un altre poble; perquè havia entrat plenament al segle $\mathrm{xx}$; atès que ja s'havia donat la Revolució Bolxevic. Molts d'ells ja portaven en la seua consciència el sindicalisme revolucionari de la CNT.

\section{La Segona República}

En el capítol Vè ens explica, a través de les fonts orals, que les persones que varen fer possible l'arribada de la República anhelaven la llibertat i el progrés i, per a ells, la llibertat significava ser lliures de l'opressió de la Monarquia, de la Dictadura i de l'Església.

Així hi diran: «Uf... disgusto con la Iglesia que nunca resolvió los problemas graves de la sociedad». Per a l'anarquista de Càlig, Amador Bonet: «La monarquia y la religión era todo una cosa». Per tant, al principi de la dècada dels vint ja s'estaven creant les condicions de l'anticlericalisme dins de sectors importants de l'esquerra social.

\section{Capítol VI . La proclamació de la Sego- na República}

Les investigacions de la doctora Martha E. Heard confirmen la tesi que la Segona República, per a la majoria del poble, era molt més que un canvi de règim. Era una revolució política i social, es tractava de construir una nova societat, a més, era una esperança d'alliberament dels poders opressors. Així que Amador Bonet, gran protagonista d'aquesta història, dirà: «La proclamació de la 
Segona República eren dies d'eufòria. La llibertat era emancipar-se de la monarquia, de la dictadura i de la majoria de l'Església».

També es confirma la tesi de la gran implantació de la ideologia republicana al conjunt del País Valencià, però ho fou de manera especial a les comarques del seu nord. Així doncs, Manuel Borrás, altre protagoniste, hi dirà: «Aquí se sacó el 80 o 90 por ciento de los votos por la República».

Però, cal dir-ho, el seu anticlericalisme estava centrat en el clero reaccionari; atès que per a ells aquest era doblement opressor: per una part, per ser reaccionaris; per l'altra, per ser feixistes; també eren nefastos perquè utilitzaven el poder de Déu per a ser més opressors. Així doncs, els anarquistes de Càlig només anaven contra el clero reaccionari, perquè ells salvaren a les monges del poble, àdhuc les integraren en la col·lectivitat, i també salvaren al canonge Luis Queixal Beltran, apodat el Canonge Rojo enfrontant-se, fins i tot, als perillosos exaltats del grup dels Inseparables. ${ }^{2}$

Així doncs, els protagonistes de Martha diuen sobre el Canonge Rojo: «Por el respeto que le tenian los de izquierdas, no lo mataron a principios de la guerra Civil [..] Después de la guerra dio muchos avales que salvaron a rojos encarcelados y puede ser que desde entonces se le conoció como el Canónigo Rojo».

A més a més, ella ressalta que la CNT a Càlig no funcionava només com un sindicat, sinó que era com si fos un partit polític àcrata; ja que marcava la política del poble amb el projecte del comunisme llibertari, tal i com succeïa a Benicarló.

Els seus protagonistes quan emigraren va ser quan van conèixer la llibertat a França. Altres com Manuel Borràs ho van fer a Barcelona. Va ser en els seues respectius llocs d'emigració on es van fer militants de la CNT i van vindre a desenvolupar aquesta ideologia al poble de Càlig.

Altrament, en el capítol VIè es confirma la tesi de la gran importància del republicanisme d'esquerres

2 Els Inseparables eren un grup, constituït per membres de la FAI vinguts de Barcelona, decidits a imposar la revolució mitjançant el terror i els assassinats. 
per a representar l'esquerra transformadora als pobles castellonencs, atès que els partits marxistes, pràcticament no hi existien, sobretot, abans de 1936.

A Canet lo Roig, el testimoniatge d'Alvaro Castell també confirmà que va ser Izquierda Republicana d'Azaña — ací era Esquerra Republicana- i no el PSOE o el PCE, els que representaven els interessos de les classes treballadores, a més de la CNT. Així que el Partit Comunista d'Espanya no es podrà implantar a Càlig fins al maig de 1937, quan és ja hegemònic arreu de l'Estat espanyol.

Segons els testimoniatges dels seus entrevistats la violència i les vagues durant la República, eren per la lentitud del projecte alliberador del Govern d'Azaña, com ara la lentitud en fer la Reforma Agrària. Aquestes vagues, anaven preparant el camí de la revolució que s'hi donà durant els tres primers mesos de la Guerra Civil.

\section{La Guerra Civil i la Revolució}

Considero que els capítols VIIè, VIIIè i IXè, és a dir, els de la Guerra Civil, són els més interessants; atès que als volts del 21 de juliol, tres dies després del colp d'estat, es donava pas a una revolució.

Així que la UGT i la CNT, com que havien lluitat pel carrer contra les forces rebels, assumiren la responsabilitat de la construcció d'una nova societat. Dit altrament, en la zona republicana, on hi havia fracassat el colp d'estat, els sindicats organitzaren aleshores els comitès antifeixistes per a la defensa del poble, però també per a fer la revolució. A Càlig la central hegemònica va ser la CNT.

La doctora Martha explica com la revolució significava la gran esperança per a una gran part de la societat, és a dir, el poder realitzar el seu projecte social i polític. En canvi, per a d'altres, era la por, la inseguretat i la mort. La revolució hi fou bastant pregona, ella ha demostrat que aquesta afectà a tots els nivells de la societat de Càlig.

El primer comitè, segons Amador Bonet fou pacífic: «Se reafirmó en la possibilidad de construir sin destruir», de fer-ho sense violència: «Se hizo la revolución para demostrar que construimos: que no era una cosa de matar y matar y matar» (Heard, 2014: 101).

Tanmateix, el segon Comitè ja fou més violent, estava «bajo el mando de 
la Comarcal de Benicarló» (Heard, o tal o cual, sin juzgarlo...!»» (Heard, 2014:122). Segons els protagonis- 2014:109).

tes de la història de Martha, una part de la violència, va ser, doncs, com a conseqüència de la revolució. Ells es preguntaven: «¿És possible construir una societat nova, fer la revolució, dins d'una guerra, però sense violència?». L'altra part, va vindre perquè entre tots plegats s'hi va construir una societat violenta.

Cal ressaltar que el procés col·lectivitzador s'inicià de seguida. Primer ficaven cartells en les finques que volien incautar. Aquests cartells els ficaren en les quatre finques dels terratinents més grans del poble. Significava, doncs, la desaparició de les classes socials, la socialització dels mitjans de producció.

Una de les principals aportacions de la professora Martha és que l'anarquisme és un moviment ideològic plural, per tant no es pot generalitzar, tot dient que els àcrates eren violents. Dins de la CNT hi havien moltes persones que eren partidaris de construir sense destruir, no eren partidaris de matar a ningú. Ramón Conesa, altre protagonista, fins i tot, arribà a dir: «(Porque, que se defiendan las ideas está muy bien. ¿Me comprendre? Pero a un extremo de matar a alguno,
Així que s'anava construint la violència, Manuel diu: «Se oían frecuentemente, en la guerra: si tu no matas, te matan»> (125). Altrament venien notícies de Saragossa que asseguraven que els franquistes assassinaven no sols als sindicalistes i als d'esquerres, sinó també a les seues famílies. Per tant, entre tots plegats vam crear una societat de la violència.

No podem oblidar mai les característiques que segons ella explicà tenia la col·lectivitat de Càlig:

La col·lectivitat de Càlig va formar part de la Federació Comarcal de Benicarló. Era una col·lectivitat agrària. Hi hagué entre quaranta sis $\mathrm{i}$ cinquanta cinc col·lectivitats, només en aquesta Comarca.

Segons Amador Bonet la col·lectivitat va complir amb la seua missió d'ajudar als menys afortunats. D'una població de 3000 habitats hi participaren unes 500 persones.

Quan ingressaven calia que ho donaren tot, sobretot allò que tenien per al camp. No era necessari ser anarquista per a formar part de la 
col·lectivitat. Els més pobres contribuïen amb els seues braços.

Encara que alguns no podien treballar, tanmateix eren ben rebuts i se'ls hi donava segons les seues necessitats. Els anarquistes demostraven la seua satisfacció per haver ajudat als més pobres i als invàlids.

Els comptes de la col lectivitat els portava un advocat, un tal Bayarri. Hi havien dos mestres refugiats que ensenyaven en l'escola racionalista de la col·lectivitat. Aquesta era com un poble unit a través de la solidaritat de classe.

La base de la col-lectivitat era l'organització del treball del camp organitzat amb delegats i quadrilles. Els delegats eren escollits per l'assemblea del dia anterior. Aquests es reunien per organitzar el treball de les diferents partides on estaven les finques col·lectivitzades.

Respecte les relacions de gènere hi havia canvis, però també continuitats. Els homes a llaurar i les dones a plegar olives i garrofes. Els homes eren els que anaven a les assemblees. De dones només hi podien assistir les vídues.

Els enfrontaments entre col·lectivistes $\mathrm{i}$ individualistes venien molt més, perquè els de la CNT no estaven a favor del Govern i el paper de la UGT era estar dintre del Govern, per aconseguir l'ajuda de les democràcies europees i guanyar la Guerra.

La doctora Martha confirma també el que diu Vicent Gavarda, quan demostra que la repressió franquista va ser molt superior i pitjor, perquè era sistemàtica amb lleis i fou després de la Guerra, és a dir, terrorisme d'Estat. Assassinats per la repressió popular a Càlig només en foren 13, en canvi els assassinat feixistes franquistes, en foren més de 30 .

En conjunt cal dir que és un bon llibre, molt interessant, amb aportacions històriques i historiogràfiques fonamentals.

\section{Vicent Grau Reig}

Doctor en Història Contemporània per la Universitat Jaume I, membre del Grup d'Estudis d'Història Local i Fonts Orals 
